\title{
Perception of friendship rewards and affiliation arousal*
}

\author{
JOHN J. LA GAIPA \\ University of Windsor, Windsor, Ont., Canada
}

Sociometric ratings were administered to fratemity $S$ s to increase anxieties over the possibility of rejection. The effects of arousal varied with the measure of need satisfaction and the kind of need. Aroused Ss rated their fraternity lower on need fulfillment than did nonaroused Ss-lower on utility $(p<.05)$ and similarity $(p<.10)$ and at the same level on ego reinforcement and authenticity. Differences in fulfillment among the four needs were accentuated in the aroused group. Need importance and equity of rewards were not influenced by arousal. The results support social exchange theory concerning the effects of situational cues on the evaluation of rewards.

Attraction to a group depends on the particular needs satisfied and the strength of these needs (Dittes, 1959). The kind of needs satisfied by friendship has received limited attention. A factor analysis has identified seven possible reward dimensions (Canfield \& La Gaipa, 1970). The friendship expectancy inventory (FEI-D) was then developed to measure the kind of rewards valued in friendship. Agreement on friendship values was found to predict attraction toward an anonymous stranger (La Gaipa \& Werner, 1971). Confirmation of expectations was also shown to be related to the growth of friendship (Lischeron \& La Gaipa, 1971). The present study was an experimental investigation of factors influencing the evaluation of the friendship rewards satisfied by group membership.

Social exchange theory (Thibaut \& Kelley, 1959) posits that the satisfaction derived from interpersonal relations is a function of the degree to which the reward costs meet or exceed the comparison level (CL). The CL is the standard by which actual rewards are evaluated and largely reflects what an individual feels he "deserves" rather than what he wants or anticipates because of his prior experiences.

Thibaut and Kelley specify some of the conditions affecting the perception of rewards and the CL. Momentary instigations may increase or decrease the perceived level of rewards without having much of an effect on the CL. Persistent, enduring experiences are essential for influencing $\mathrm{CL}$. The rewards likely to be made salient by situational cues are those rewards perceived as within the realm of personal control and self-responsibility. Perceived status is such an outcome, since status depends

* The author is indebted to Joseph A. Lischeron for his help and to Arthur Smith and Meyer Starr for their useful comments. in part on the degree and kind of rewards and costs provided others.

Sociometric ratings were used in the present study to instigate the saliency of perceived status and reward costs in a group. Studies on affiliation arousal, as reviewed by Mehrabian \& Ksionzky (1970), indicate that sociometric ratings typically induce anxiety over the possibility of rejection. It was predicted that arousal should interact with the kind of social need in determining the perception of the amount of reward obtained and have little effect on how much "should" be obtained or the value of the rewards. MATERIALS

The rating format used in the Porter (1961) need satisfaction questionnaire was adopted in constructing the FEI-G. The FEI-D, used in previous research, measures reward value only and is useful for studying dyads. The FEI-G provides, instead, three dimensions of need satisfaction and is suitable for examining evaluative responses to a larger group. Four FEI-D scales were substituted for the Maslow-type scales in the Porter questionnaire. Validity data (Lischeron \& La Gaipa, 1971) were used in the selection of these scales. The social desirability of the four scales was also determined by administering the Marlowe-Crowne MC-SD scale (Crowne \& Marlowe, 1960 ) and the FEI-D scales to 101 male University of Windsor students. The mean correlation of the four scales with the MC-SD scale was .12. Reliability was estimated from FEI-D data obtained on 134 male Wayne State University students. The mean alpha reliability was .79 .

The four FEI-G scales, and an example of an item in each scale, are as follows: utility (could turn to them for support in time of need); authenticity (feel free to be my own genuine self with them); ego reinforcement (feel that I am an important, worthwhile person); and similarity (we have many common interests). Need satisfaction obtained from the group was assessed by responses to 20 statements. For each quality, three ratings are requested: (1) How much of the characteristic is there now; (2) How much of the characteristic do you think should be obtained from belonging to a group such as this? and (3) How important is this characteristic to you? The Ss circle a number on a rating scale from 1 to 7 , with the low numbers representing minimum amounts and the high numbers representing maximum amounts. The scoring consists of summing the responses to each of the five items in each of the four need areas. The evaluation ratings represent (1) need fulfillment, (2) perceived equity, and (3) need importance, respectively. A total of 12 scores were computed on each $\mathrm{S}$. The postexperimental questionnaire consisted of a single-item anxiety-reaction scale used by Schachter (1959) in studying anxiety and affiliation. The Ss indicated on a 6-point scale the degree of uneasiness experienced in the experiment.

\section{PROCEDURE}

The basic procedure is described in greater detail elsewhere (Atkinson et al, 1954). Briefly, two fraternities at the University of Michigan were selected randomly to serve as the arousal group $(\mathrm{N}=30)$ and the nonarousal group $(N=30)$. Comparative data indicated that the two fraternities were quite similar in size, social background, and group cohesiveness. Each fraternity received $\$ 25$ for participation in the study. The aroused Ss were administered a sociometric task with instructions to list the names of their three closest friends in the fraternity and the names of the fraternity brothers liked, disliked, and undecided about. Ambiguity was fostered as to subsequent feedback to allow the Ss to anticipate the possibility of rejection. The nonaroused Ss were administered an anagrams task with instructions to make as many words out of the word "generation" as possible within $7 \mathrm{~min}$. This task served to decrease any affiliation motivation cues in the situation by means of incompatible achievement cues. Both groups were administered the FEI-G and the postexperimental questionnaire upon completion of their respective tasks.

\section{RESULTS}

The effectiveness of the experimental manipulation was assessed by means of the postexperimental rating scale. The aroused Ss expressed a higher level of anxiety $(p<.01)$ than the nonaroused Ss.

A 2 by 4 by 3 analysis of variance 


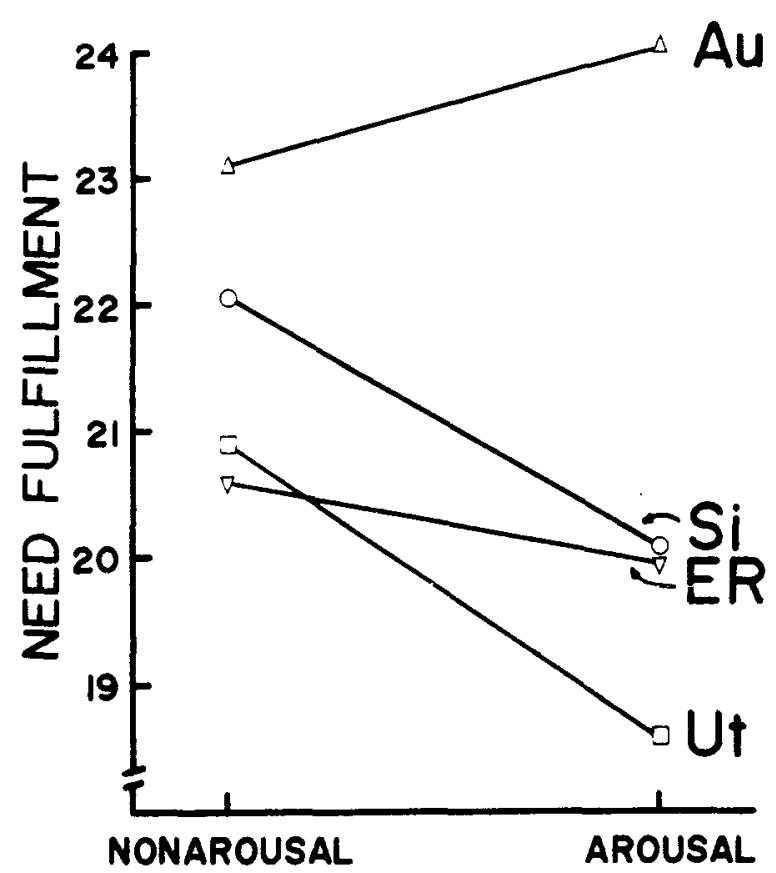

Fig. 1. Mean fulfillment by arousal and need type: authenticity (Au), similarity (Si), ego reinforcement (ER), and utility (Ut).

design was used with repeated measures on the last two factors. Arousal had no significant main effect on the evaluation ratings. Significant main effects were obtained for need type $(p<.001)$ and the evaluation mode $(p<.001)$. The Need Type by Evaluation Mode interaction was significant $(\mathrm{p}<.001)$, indicating that the ratings of different social needs varies as a function of the evaluation measure used. The Arousal by Need Type interaction effects on each of the three ratings were also examined. No significant interaction effects were found on equity or importance. The Arousal by Need Type interaction on need fulfillment was significant $(\mathrm{p}<.01)$.

Figure 1 depicts the mean need fulfillment scores for each of the four social needs under nonarousal and arousal. One source of the Arousal by Need Fulfillment interaction is suggested by the lower ratings of utility $(\mathrm{p}<.05)$ and similarity $(p<.10)$ in the aroused than in the nonaroused group. A second source of the interaction is also evident. The effects of need type were significant for both the aroused group $[F(3,522)$ $=16.29, p<.001]$ and the nonaroused group $[\mathrm{F}(3,522)=3.92$, $\mathrm{p}<.01]$. It may be observed in Fig. 1 that authenticity was rated the highest under both conditions, though at about the same level of fulfillment. In the aroused group, the other three needs were rated at a significantly lower level than authenticity (Scheffé test. $\left.a_{2}=.01\right)$. This greater difference among the needs under arousal is indicated by the significant Arousal by Need Type interaction.

The variances and the correlations between the ratings were also subjected to post hoc analyses. The rationale for examining the variances was that stress and anxiety may affect variability without necessarily showing a main effect. For the need fulfillment scores, a significantly higher variability, using a one-tailed test, was found under arousal than under nonarousal for ego reinforcement $[F(29,29)=2.10, p<.05]$ and utility $[F(29,29)=3.82, p<.001]$. The correlations between ratings of need fulfillment and importance were significant $(p<.02)$ under arousal and not under nonarousal $(p>.05)$ for ego reinforcement $(.46$ vs .07), authenticity $(.56$ vs .19), and similarity (.43 vs .26$)$, respectively. The rs for utility ratings were nonsignificant $(p>.05)$ under arousal (.34) and significant $(\mathrm{p}<.02)$ under nonarousal (.45).

\section{DISCUSSION}

The predictions made from social exchange theory were supported: arousal had a differential effect on need fulfillment, and no significant effect on the equity and importance of the needs. The lower fulfillment ratings on two of the four needs may reflect differences in the degree of personal control or perceived ability to provide these rewards to others. Perhaps it is psychologically less demanding on a person to provide material or nonmaterial support than to be open and authentic. It is also conceivable that a social group may be perceived as having a greater potential for satisfying some needs than others. Stephen et al (1971) found that the effects of arousal on person perception varied according to the drive relevance of the dimension. Other theoretical constructs may be useful in accounting for the differential effects of arousal.

The predictions made from social exchange theory in this study are limited to the effects of situational cues or momentary instigations. Repeated, enduring experiences may affect $C L$. A related proposition in exchange theory is that the rewards obtained and the $\mathrm{CL}$ become more closely aligned over a period of time. It will be recalled that significant relationships were found under arousal between need fulfillment and need importance. It could be that arousal has a short-term effect in decreasing the difference between the scale values on these two dimensions. But it is also possible that fewer discriminations were made between these dimensions. An increase in drive level may lead to a reduction in cue utilization and have a dysfunctional effect (Bruning et al, 1968).

An unexpected finding was that the differences in need fulfillment as a function of need type were greater under arousal than under nonarousal. Tajfel (1957) posits that there may be an accentuation of the differences between valued and neutral stimuli in order to increase the likelihood of a successful response. High drive, then, might accentuate the apparent difference between needs that are relatively "neutral" and those that have emotional significance.

The effects of arousal may also be interpreted by the reinforcement model of evaluative responses developed by Byrne \& Clore (1971). In this classical conditioning model, arousal can be conceived as an unconditioned stimulus (UCS). As a result of the association with UCS, the stimulus persons function as the conditioned stimulus (CS). The implicit affective responses elicited by CS mediate the overt evaluative responses. The need fulfillment ratings, then, would be mediated by the negative affect generated by the stimulus persons. Gouaux (1971), in support of this model, found that induced negative affective states evoke negative interpersonal evaluations.

In summary, this study suggests that momentary situational factors may have little effect on the value of the rewards derived from friendship or on whether a person feels he is getting an equitable share from belonging to a group. The perception of the amount obtained, however, may be affected 
depending on the kind of reward. The possible effects of more enduring, persistent factors require further investigation.

\section{REFERENCES}

ATKINSON, J. W. HEYNS, R. W., \& VEROFF, J. The effect of experimental arousal of the affiliation motive on thematic apperception. Joumal of Abnormal \& Social Psychology, 1954, 49, 405-410.

BYRNE, D., \& CLORE, G. L. A reinforcement model of evaluative responses. Personality: An international Journal, 1970, 1, 103-128.

BRUNING, J. L.. CAPAGE, J. E., KOZUH G. F., YOUNG, P. F., \& YOUNG,W. E. Socially induced drive and range of cue utilization. Journal of Personality \& Social Psychology, 1968, 9, 242-244

CANFIELD, F. E., \& LA GAIPA, J. J. A multidimensional approach to friendship. Canadian Psychologist, 1970, 11, 179. (Abstract)

CROWNE, D. P., \& MARLOWE, D. A new scale of social desirability independent of psychopathology. Journal of Consulting Psychology, 1960, 24, 349-354.

DITTES, J. E. Attractiveness of group as a function of self-esteem and acceptance by group. Journal of Abnormal \& Social Proup. Journal of Abnormalogy, 1959, 59, 77-82.

GOUAUX, C. Induced affective states and interpersonal attraction. Journal of Personality \& Social Psychology. 1971. $20,37-43$.

LA GAIPA, J. J., \& WERNER, R. E. Effects of topic relevancy and attitude similarity on two measures of affiliation. Psychonomic Science, 1971, 24, 67-68.

LISCHERON, J. A., \& LA GAIPA, J. J. The friendship expectancy inventory: Prediction of the growth of friendship. Canadian Psychologist, 1971, 12, Suppl.
No. 2, 194. (Abstract)

MEHRABIAN, A., \& KSIONZKY, S. Models for affiliative and conforming behavior. Psychological Bulletin, 1970, 74, 110-126.

PORTER, L. W. A study of perceived need satisfaction in bottom and middle management jobs. Journal of Applied Psy chology, 1961, 45, 1-10.

SCHACHTER, S. The psychology of aifiliation. Stanford: Stanford University Press, 1959.

STEPHAN, W., BERSCHEID, E., \& WALSTER, E. Sexual arousal and heterosexual perception. Journal of Personality \& Social Psychology, 1971, 20, 93-101.

TAJFEL, $H$. Value and the perceptual judgment of magnitude. Psychological Review, 1957, 64, 192-204.

THIBAUT, J. W., \& KELLEY, H. H. The social psychology of groups. New York: Wiley, 1959. 